\title{
Multi-Criteria Evaluation of Design Complexity for Patient-Specific Bone Graft
}

\author{
Boris AGARSKI, Mario SOKAC, Zeljko SANTOSI, Djordje VUKELIC, Igor BUDAK
}

\begin{abstract}
With the rise of modern computer-aided technologies, their use in various different fields is becoming more and more apparent, but more profoundly in the field of medicine. The use of such technology enables the design of complex anatomical structures, often found in different areas of medicine. Maxillofacial and oral fields are becoming more and more popular with the use of such technologies, all leaning toward designing and fabrication of patient-specific implants from a biocompatible material. The level of complexity in personal graft design depends on criteria that describe the bone graft's various properties. This research applies multi-criteria decision aiding in selection of patient-specific bone graft optimal design.Twelve different patient-specific bone-grafts designs have been evaluated by four decision makers who expressed their preferences with direct weighting and revised Simos procedure. Well known VIKOR method was used for multi-criteria decision aiding and the final results verified that the fully curved shape graft design is the least complex while the complex shape is the most demanding from the graft design perspective.
\end{abstract}

Keywords: design; implant; multi-criteria evaluation; patient-specific bone-grafts

\section{INTRODUCTION}

In today's modern field of biomedical engineering, application of different tools from different fields of science, enables its growing at a fast pace, and, as such, it finds itself today to be far beyond the original borders of traditional engineering [1]. This, aided in its expansion to other fields of science, creates an innovative multidisciplinary field that puts emphasis on the need for cooperation between engineers and surgeons. By doing this, collaboration between engineers and doctors enables rapid spreading to different fields of medicine, and one of them is the field of dentistry and oral surgery [2]. Oral surgeons have multiple benefits of incorporation of such 3D technologies, as it aids them in achieving better technical aspects of different types of implants, thus improving their work and providing better medical treatments. Fulfilments of both functional and aesthetic requirements present the main task of all dental restorations. Application of reverse engineering (RE) in the field of dentistry has greatly facilitated the modelling and designing aspects. For the purpose of creating virtual 3D models, many 3D digitizing methods have been developed in the field of RE [3]. With the introduction of additive manufacturing technologies in the medical field, this has produced a strong bond in combination of these two emerging fields $[4,5]$. By designing complex shapes and structures using RE modelling approach, they can be transferred afterwards to be manufactured using additive manufacturing technologies $[6,7]$. This ensures that all necessary preliminary steps are taken into account in order to successfully provide adequate medical care to the patients.

One of the key challenges in the field of oral surgery today presents the restoration of bone defects in the oral cavity which usually occur after simple tooth extraction, or due to some infections, tumour, trauma, cyst or other circumstances [8]. Reconstruction of these defects occurs using patient-specific bone-grafts, tailored to each patient specifically. However, there are several factors that have to be taken into account when it comes to designing a patientspecific bone-graft. They include its position, overall dimensions, design type, etc. and choosing the optimal set sometimes can present a difficult task [9].
In biomedical engineering for designing patientspecific implants, the selection of optimal shape strongly depends on different criteria based on the specific insertion area. In order to successfully implement a certain design, which can vary due to the different criteria, a normalization process is needed for the selection. Considering that health care decision making is a complex task, multi-criteria decision aiding (MCDA) has been applied for evaluation of various alternatives in medical and health solutions. MCDA, as such tool, was used in different scenarios for assessment and optimization of the size of hip implant to reduce the problem of stress shielding [10]. Considering the fact that the knee joint is one of the largest and most complex joints in the human body, Vukelic et al. [11] applied MCDA and life cycle assessment in order to select the optimal knee support. From a reconstructive surgery standpoint, MCDA is also being used for evaluation of preoperative designs for reconstructions of cranial defects regarding their mechanical robustness using finite element modelling. MCDA has also been used, according to authors in [12], for improving quality of design in femoral component of knee prostheses, where authors investigated the influence of interface geometry and material of the knee prostheses. VIKOR, as an MCDA method, has been also used for material selection [13]. Use of MCDA to support decision making in clinical research, in order to clarify available evidence, prioritize research questions, and to address the most critical research needs, has been discussed in [14]. In [15] MCDA was applied to obtain preferences and views on decision criteria across three stakeholder groups (patients, clinicians and payers) in Italy and to use these to assess the performance of obinutuzumab for rituximab-refractory indolent non-Hodgkin lymphoma. A comprehensive review of MCDA applications in health care is provided in [16] where 66 studies have been systematically organized and analysed. Furthermore, a review of MCDA models in health technology assessment of orphan drugs has been analysed in [17].

Several approaches for MCDA in solving the product/process design have been developed, and further text mentions some of them. Crnjac et al. [18] developed the methodology for product design selection based on MCDA PROMETHEE and Taguchi method. They used PROMETHEE for selecting the most suitable design, 
while the Taguchi method was used to define the most appropriate parameters for selected suitable design. Szafranko [19] applied MCDA to aid the planning and design of building projects where the choice of optimal material and technology solutions has to be made. Vilke et al. [20] defined the model for evaluation of transport planning and designing with MCDA. Presented model for MCDA was applied in the evaluation and selection of the Jelšane - Postojna highway route by using the PROMETHEE II method for the multi-criteria ranking of alternatives. Šarić et al. [21] used multi-criteria ABC analysis, neural networks and cluster analysis to support inventory classification in production companies. Furthermore, they investigated the results obtained by AHP, neural network model, and cluster analysis model in order to check the consistency of the inventory classification results. Jiang and Liu [22] used fuzzy correlation entropy and particle swarm optimization in order to solve a multi-objective optimization problem in cloud manufacturing-a service-oriented manufacturing environment.

According to previous research, none of the authors applied MCDA for defining the criteria and evaluation of design complexity for patient-specific bone-grafts production. Therefore, the goal of this research is to develop an MCDA approach for selection of optimal patient-specific bone-graft design. More specifically, this research provides a framework of criteria for evaluation of the level of complexity in patient-specific bone-graft design. The developed MCDA approach aims to benefit for future selection of optimal design in a way that enables more convenient selection based on a predefined criteria.

The remainder of the paper is organised as follows. Section 2 describes the developed methodology. Section 3 presents the MCDA results for different patient-specific bone-graft designs. Section 4 provides discussion of obtained results. Section 5 includes conclusions, limitations and future research directions.

\section{METHODOLOGY}

Developed approach for evaluation of the level of complexity in patient-specific bone-graft design is based on MCDA and consists of the following steps:

- Defining the framework of evaluation criteria,

- Defining the alternatives,

- Formation of performance matrix,

- Criteria weighting with direct weighting and revised Simos procedure (RSP),

- MCDA with VIKOR,

- Ranking of alternatives.

The first step in MCDA is to define the criteria and framework for evaluation of the level of complexity in patient-specific bone-graft design (Fig. 1). The criteria for evaluation of the level of complexity in patient-specific bone-graft design are grouped as follows:

- Economic criteria: modelling cost, cost of a biocompatible material block.

- Feasibility criteria: position on the jaw, negative angles, sharp edges, bone porosity.

- Geometry criteria: graft dimensions, graft thickness, graft shape and number of needed implants.
Criteria for evaluation of the level of complexity in personal graft design are explained as:

- EC1 - modelling cost - presents the cost of patientspecific bone-graft modelling design, expressed in euros;

- $E C 2$ - the cost of material - is the cost of fabrication of patient-specific bone-graft from a biocompatible material block, expressed in euros.

- $F C 1$ - position on the jaw - presents the location of the implant on the upper jaw (maxilla) or lower jaw (mandible). This position is expressed as: 1 - low complexity lower jaw, 2 - high complexity lower jaw, 3 - low complexity upper jaw, 4 - medium complexity upper jaw, 5 - high complexity upper jaw.

- $F C 2$ - negative angles - is the total number of negative angles present on the modelled geometry. Based on the author's previous experience no more than five negative angles were present on modelling geometry. However, it is plausible for the geometry to have more than five negative angles.

- FC3 - sharp edges - depending on the shape of the implant site, there can be up to five present sharp edges, depending on the insertion site of the patientspecific implant.

- FC4 - bone porosity - depending on the current condition of the implant site there can be either: 1 - no bone porosity, 2 - low bone porosity, 3 - medium bone porosity, 4 - high bone porosity.

- FC5 - the presence of artefacts - artefacts present artificial structure that does not correspond to the actual condition [23]. Medical CT images can either have the presence of artefacts on them (value 2 in MCDA) or not (value 1 in MCDA).

- $G C 1$ - patient-specific bone-graft volume - presents the total volume of the fabricated patient-specific bone-graft from the biocompatible block;

- GC2 - deviation from recommended graft thickness based on guidelines from manufactures of a biocompatible material, it is recommended that optimal value for graft thickness should be around 3 $\mathrm{mm}$. Thickness lower than recommended could cause the patient-specific bone-graft to break during a surgical procedure. On the other hand, thickness larger than recommended could cause issues with osseointegration due to low blood circulation.

- $G C 3$ - patient-specific bone-graft shape - four types of patient-specific bone-graft shapes can be distinguished: fully curved shape (FC shape), partially curved shape (PC shape), L shape and complex shape (Fig. 2). PC shape is designed to cover the top of the alveolar ridge, while the FC shape is designed to add more support to the sides of the insertion site. L shape design is used for bone ridge augmentation on the upper jaw, for adding more bone structure to the front side. Finally, the complex shape design covers the unorthodox and unsymmetrical shapes that could come up in practice.

- $G C 4$ - number of needed implants - depending on the number of required implants, patient-specific bonegrafts can be designed to facilitate up to three implants. 


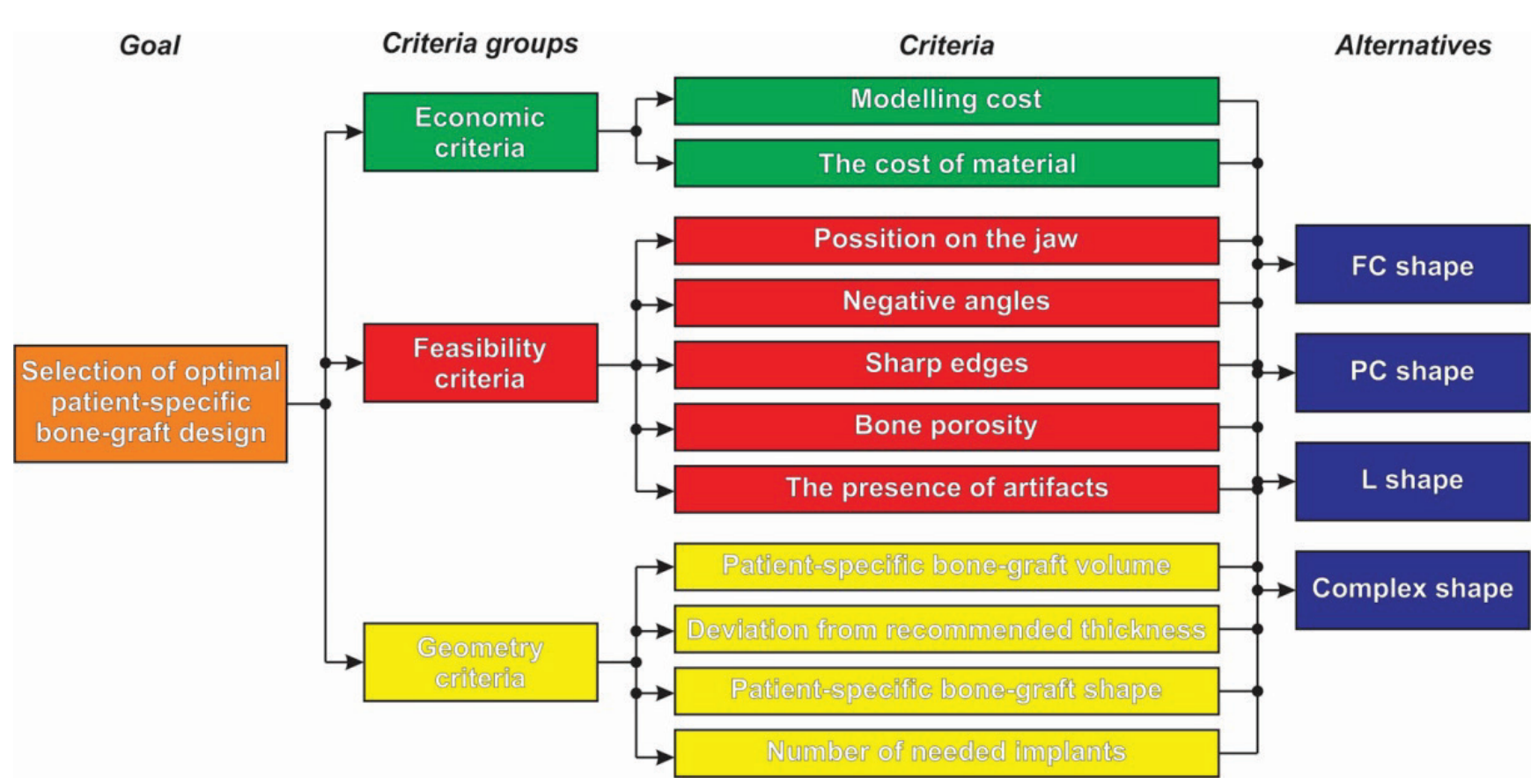

Figure 1 Framework for selection of optimal patient-specific bone-graft design

The second step is to define the patient-specific bonegraft design alternatives. Patient-specific bone-grafts can be produced for one, two or more implants. As previously stated, patient-specific bone-grafts can be grouped in four shapes: FC shape, PC shape, L shape, and complex shapes depending on the patient-specific implementation site.

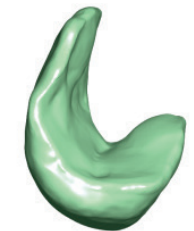

a)

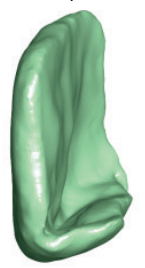

c)

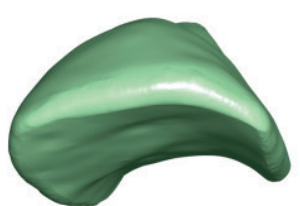

b)

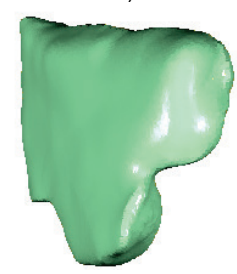

d)
Figure 2 Patient-specific bone-graft shape a) FC; b) PC; c) L; d) Complex

After the criteria and alternatives are defined, the performance matrix can be assembled. Some criteria are quantitative $(E C 1, E C 2, G C 1, G C 2)$, while qualitative criteria $(F C 1-5, G C 3, G C 4)$ are translated to quantitative values with consensus in group decision making.

Criteria weighting is performed with group decision making with direct weighting $(D W)$ and RSP. Two weighting methods are used in order to investigate the decision makers consistency and deviations between the criteria weights obtained through direct weighting and RSP. First the decision maker expresses its preferences with direct weighting and after he tries to replicate his values through the RSP. The decision-maker in $D W$ assigns numbers representing criteria weight directly according to his preferences. The criteria weights are first assigned to criteria groups and after to criteria within the criteria group.
The final criteria weights is obtained by multiplying the weight from criteria group and criterion weight within the same criteria group. Next weighting method in MCDA approach, uses RSP [24] that is based on previously developed weighting method $[25,26]$. Therefore, the new RSP considers the ratio between the most and least important criteria weighting, additional information from the decision maker, as well as adjusted computing rules.

Performance matrix and criteria weights are input in VIKOR method. The VIKOR method determines the compromise ranking-list, the compromise solution, and the weight stability intervals for preference stability of the compromise solution obtained with the initial (given) criteria weights [27]. In VIKOR the multi-criteria ranking index is based on the measure of "closeness" to the "ideal" solution. A detail description of VIKOR method is available in [27]. The output from VIKOR, and final output of MCDA, is $Q$ value that indicates the total level of complexity for patient-specific bone-graft design solution. Higher $Q$ values indicate a more complex design of patientspecific bone-graft and vice versa. Based on MCDA result, patient-specific bone-graft designs are ranked and the optimal solution is identified.

\section{RESULTS}

Following the methodology presented in the previous chapter, the criteria have been defined as in Fig. 1. The alternatives are three variations of FC shape, PC shape, L shape and complex shape, i.e. twelve alternatives for MCDA evaluation (Fig. 3).

In this case study, three studies for designing patientspecific implants on three patients were presented. Four shapes were selected because they represent four basic types that can be met when designing patient-specific implants. Besides presented shapes, there perhaps could be situations where two different shapes can be applied for the same case, but this has not been considered, and it was not applicable in this research. The designed shapes of patient- 
specific bone-grafts are fabricated from biocompatible material (which can be made, for example from natural mineral matrix - Calcium Hydroxyapatite).

The performance matrix was assembled and values have been defined for all patient-specific bone-graft designs according to previously defined criteria (Tab. 1). Values for qualitative criteria $(F C 1-5, G C 3, G C 4)$ are obtained through consensus in group decision making where four decision makers participated. Decision makers are two biomedical engineering designers for medical implants (DM1 and DM2) and two oral surgeons (DM3 and $D M 4)$. Decision makers previous experience was key parameter for participation, as each of them has multiple years of experience in his respective field.

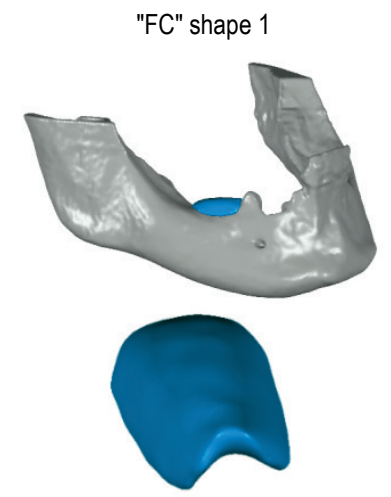

"PC" shape 1
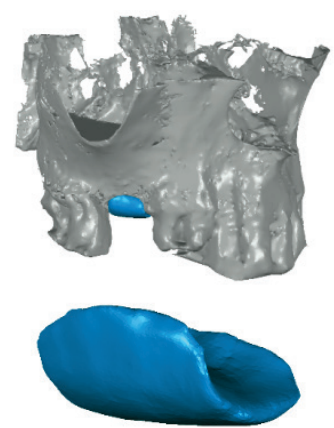

"L" shape 1
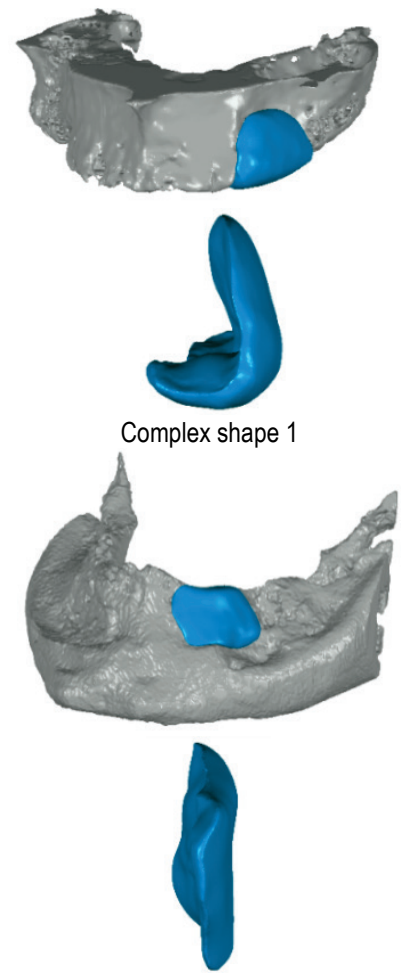

"FC" shape 2

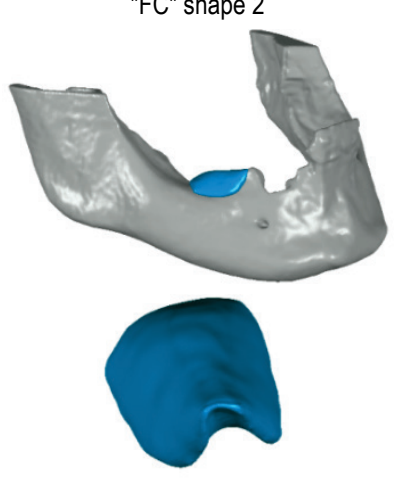

"PC" shape 2
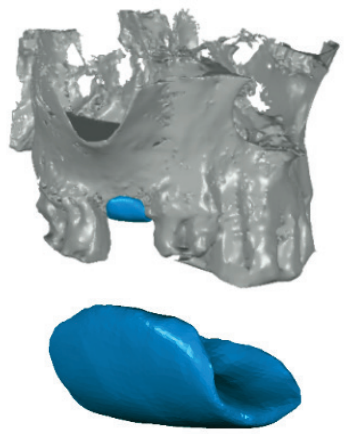

"L" shape 2
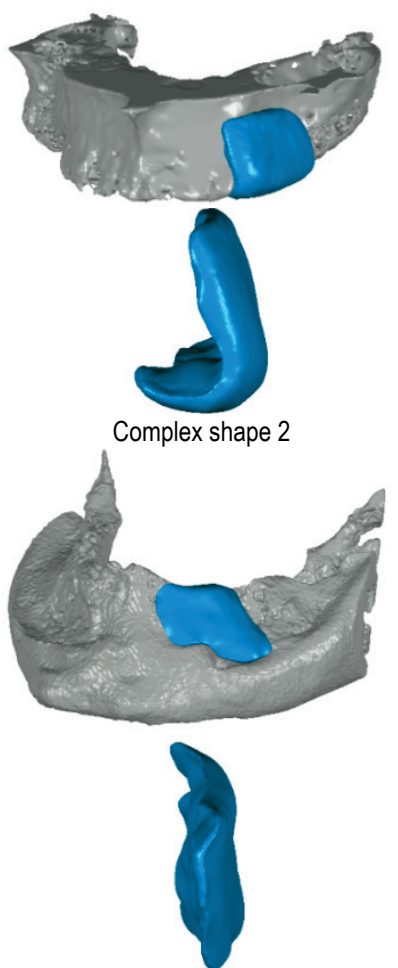

"FC" shape 3

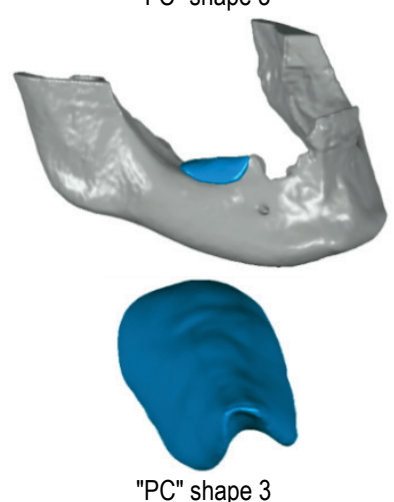

"PC" shape 3
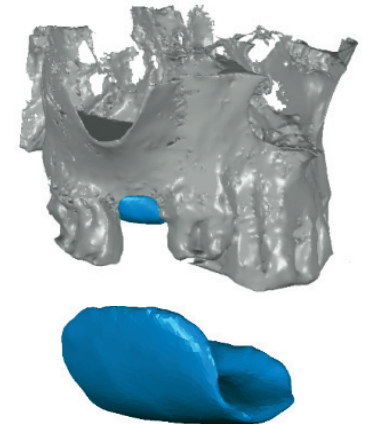

"L" shape 3

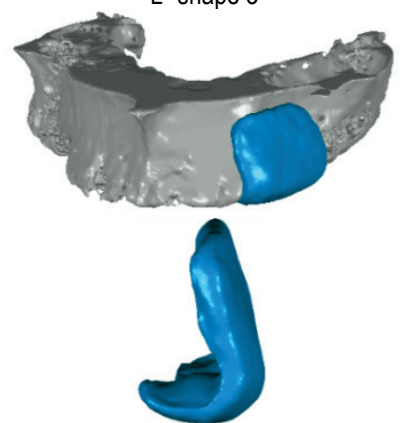

Complex shape 3

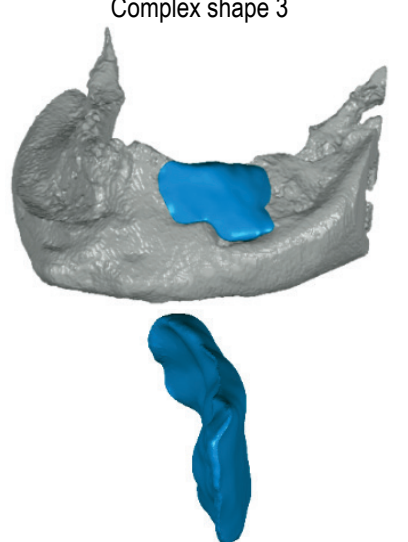

Figure 3 Twelve patient-specific bone-graft shape alternatives - three patient-specific bone-graft variations of FC shape, PC shape, L shape and complex shape 
Table 1 Performance matrix

\begin{tabular}{|c|c|c|c|c|c|c|c|c|c|c|c|}
\hline Criteria & $E C 1$ & $E C 2$ & $F C 1$ & $F C 2$ & $F C 3$ & $F C 4$ & $F C 5$ & $G C 1$ & $G C 2$ & $G C 3$ & $G C 4$ \\
\hline Unit & $€$ & $€$ & / & 1 & / & 1 & / & $\mathrm{mm}^{3}$ & $\mathrm{~mm}$ & $/$ & 1 \\
\hline Criteria type & $\min$ & $\min$ & $\min$ & $\min$ & $\min$ & $\min$ & $\min$ & $\min$ & $\min$ & $\min$ & $\min$ \\
\hline Ideal & 50 & 70 & 1 & 1 & 1 & 1 & 1 & 100 & 0 & 1 & 1 \\
\hline Anti-ideal & 450 & 600 & 5 & 5 & 5 & 4 & 2 & 2000 & 7 & 4 & 3 \\
\hline FC shape 1 & 70 & 100 & 1 & 1 & 1 & 1 & 1 & 371 & 1,39 & 2 & 1 \\
\hline FC shape 2 & 180 & 140 & 1 & 1 & 1 & 1 & 1 & 547 & 2,59 & 2 & 1 \\
\hline FC shape 3 & 210 & 180 & 2 & 1 & 1 & 1 & 1 & 680 & 2,95 & 2 & 2 \\
\hline PC shape 1 & 80 & 60 & 4 & 1 & 1 & 2 & 1 & 138 & 0,63 & 1 & 1 \\
\hline PC shape 2 & 90 & 60 & 4 & 1 & 1 & 3 & 1 & 161 & 0,13 & 1 & 1 \\
\hline PC shape 3 & 100 & 60 & 5 & 1 & 1 & 4 & 1 & 169 & 0,26 & 1 & 1 \\
\hline L shape 1 & 150 & 200 & 5 & 2 & 2 & 2 & 1 & 598 & 0,42 & 3 & 1 \\
\hline L shape 2 & 180 & 240 & 5 & 3 & 2 & 3 & 1 & 797 & 0,28 & 3 & 1 \\
\hline L shape 3 & 200 & 290 & 5 & 3 & 2 & 3 & 1 & 880 & 0,72 & 3 & 2 \\
\hline Complex shape 1 & 250 & 200 & 2 & 1 & 2 & 3 & 1 & 453 & 0,41 & 4 & 1 \\
\hline Complex shape 2 & 275 & 250 & 2 & 2 & 3 & 3 & 1 & 766 & 0,09 & 4 & 2 \\
\hline Complex shape 3 & 330 & 320 & 2 & 3 & 3 & 3 & 1 & 966 & 0,12 & 4 & 3 \\
\hline
\end{tabular}

Criteria weighting was first performed with a direct assignment of criteria weights, individually for each decision maker. Weighing coefficients for previously defined criteria are shown in Tab. 2 for direct criteria weighting and Tab. 3 for weighting with RSP.

Table 2 Direct criteria weighting

\begin{tabular}{|c|c|c|c|c|c|c|c|c|c|c|c|c|c|}
\hline \multirow{2}{*}{ Criteria group } & \multicolumn{4}{|c|}{ Criteria group weights } & \multirow{2}{*}{ Criteria } & \multicolumn{4}{|c|}{$\begin{array}{l}\text { Individual criteria weights } \\
\text { (within the criteria group) }\end{array}$} & \multicolumn{4}{|c|}{ Criteria weights } \\
\hline & $D M 1$ & $D M 2$ & $D M 3$ & $D M 4$ & & $D M 1$ & $D M 2$ & $D M 3$ & $D M 4$ & $D M 1$ & $D M 2$ & $D M 3$ & $D M 4$ \\
\hline \multirow{2}{*}{$\begin{array}{c}\text { Economic } \\
\text { criteria }\end{array}$} & \multirow{2}{*}{0,20} & \multirow{2}{*}{0,70} & \multirow{2}{*}{0,10} & \multirow{2}{*}{0,15} & $\mathrm{EC} 1$ & 0,40 & 0,65 & 0,40 & 0,30 & 0,08 & 0,46 & 0,04 & 0,05 \\
\hline & & & & & $\mathrm{EC} 2$ & 0,60 & 0,35 & 0,60 & 0,70 & 0,12 & 0,25 & 0,06 & 0,11 \\
\hline \multirow{5}{*}{$\begin{array}{c}\text { Feasibility } \\
\text { criteria }\end{array}$} & \multirow{5}{*}{0,50} & \multirow{5}{*}{0,15} & \multirow{5}{*}{0,30} & \multirow{5}{*}{0,20} & FC1 & 0,15 & 0,10 & 0,30 & 0,40 & 0,08 & 0,02 & 0,09 & 0,08 \\
\hline & & & & & $\mathrm{FC} 2$ & 0,10 & 0,15 & 0,10 & 0,15 & 0,05 & 0,02 & 0,03 & 0,03 \\
\hline & & & & & FC3 & 0,05 & 0,15 & 0,10 & 0,20 & 0,03 & 0,02 & 0,03 & 0,04 \\
\hline & & & & & FC4 & 0,30 & 0,30 & 0,30 & 0,15 & 0,15 & 0,05 & 0,09 & 0,03 \\
\hline & & & & & FC5 & 0,40 & 0,30 & 0,20 & 0,10 & 0,20 & 0,05 & 0,06 & 0,02 \\
\hline \multirow{4}{*}{$\begin{array}{l}\text { Geometry } \\
\text { criteria }\end{array}$} & \multirow{4}{*}{0,30} & \multirow{4}{*}{0,15} & \multirow{4}{*}{0,60} & \multirow{4}{*}{0,65} & $\mathrm{GC} 1$ & 0,25 & 0,20 & 0,15 & 0,20 & 0,08 & 0,03 & 0,09 & 0,13 \\
\hline & & & & & $\mathrm{GC} 2$ & 0,20 & 0,25 & 0,20 & 0,15 & 0,06 & 0,04 & 0,12 & 0,10 \\
\hline & & & & & GC3 & 0,40 & 0,25 & 0,30 & 0,40 & 0,12 & 0,04 & 0,18 & 0,26 \\
\hline & & & & & GC4 & 0,15 & 0,30 & 0,35 & 0,25 & 0,05 & 0,05 & 0,21 & 0,16 \\
\hline
\end{tabular}

Table 3 Criteria weighting with RSP

\begin{tabular}{|c|c|c|c|c|c|c|}
\hline \\
\hline$r$ & Criteria in rank $r$ & $e_{r}^{\prime}$ & $k(r)$ & Total & $k^{*}$ & $k^{* * *}$ \\
\hline \multicolumn{7}{|c|}{ Decision maker $1(z=6)$} \\
\hline 6 & $F C 1, G C 1$ & 0 & 1 & 1,0000 & 2,0000 & 0,0628 \\
\hline 5 & $F C 2, F C 3$ & 0 & 1 & 1,8333 & 3,6667 & 0,1152 \\
\hline 4 & $G C 2, G C 3, G C 4$ & 0 & 1 & 2,6667 & 8,0000 & 0,2513 \\
\hline 3 & $E C 1$ & 0 & 1 & 3,5000 & 3,5000 & 0,1100 \\
\hline 2 & $F C 4, E C 2$ & 1 & 2 & 4,3333 & 8,6667 & 0,2723 \\
\hline 1 & $F C 5$ & 0 & 0 & 6,0000 & 6,0000 & 0,1885 \\
\hline \multicolumn{7}{|c|}{ Decision maker $2(z=6)$} \\
\hline 7 & $G C 2$ & 0 & 1 & 1,0000 & 1,0000 & 0,0278 \\
\hline 6 & $G C 1, G C 4$ & 0 & 1 & 1,8333 & 3,6667 & 0,1016 \\
\hline 5 & $G C 3, F C 3$ & 0 & 1 & 2,6667 & 5,3333 & 0,1482 \\
\hline 4 & $F C 1, F C 2, F C 4$ & 0 & 1 & 3,5000 & 10,5000 & 0,2917 \\
\hline 3 & $F C 5$ & 0 & 1 & 4,3333 & 4,3333 & 0,1204 \\
\hline 2 & $E C 2$ & 0 & 1 & 5,1667 & 5,1667 & 0,1435 \\
\hline 1 & $E C 1$ & 0 & 0 & 6,0000 & 6,0000 & 0,1667 \\
\hline \multicolumn{7}{|c|}{ Decision maker $3(z=6)$} \\
\hline 6 & $E C 1, E C 2$ & 0 & 1 & 1,0000 & 2,0000 & 0,0498 \\
\hline 5 & $G C 1$ & 0 & 2 & 1,8333 & 1,8333 & 0,0456 \\
\hline 4 & $F C 5, F C 3, F C 2$ & 0 & 1 & 3,5000 & 10,5000 & 0,2614 \\
\hline 3 & $G C 3$ & 0 & 1 & 4,3333 & 4,3333 & 0,1079 \\
\hline 2 & $G C 2, F C 1, G C 4$ & 0 & 1 & 5,1667 & 15,5000 & 0,3859 \\
\hline 1 & $F C 4$ & 0 & 0 & 6,0000 & 6,0000 & 0,1494 \\
\hline \multicolumn{7}{|c|}{ Decision maker $4(z=5)$} \\
\hline 5 & $E C 1, E C 2, F C 5$ & 0 & 1 & 1,0000 & 3,0000 & 0,1006 \\
\hline 4 & $G C 1$ & 0 & 1 & 1,8333 & 1,8333 & 0,0615 \\
\hline 3 & $F C 4, F C 2, G C 2, F C 3$ & 1 & 2 & 2,6667 & 10,6667 & 0,3575 \\
\hline 2 & $G C 4$ & 0 & 1 & 4,3333 & 4,3333 & 0,1453 \\
\hline 1 & $F C 1, G C 3$ & 0 & 0 & 5,0000 & 10,0000 & 0,3352 \\
\hline
\end{tabular}

Note: $E C 1-2, F C 1-5, G C 1-4=$ criterion; $e_{r}^{\prime}=$ number of white cards according to rank $r ; k(r)=$ non-normalized criteria weights; $k^{*}=$ normalized criteria weights; $k^{* *}=$ normalized criteria weights of each criterion in the rank; $r=$ criterion rank; RSP = revised Simos procedure; Total = number of criteria in rank $r$ multiplied by $k(r) ; z=$ ratio of most to least important criteria. 
The calculated criteria weights are shown in Fig. 4. The results from VIKOR, calculated $Q$ values, are shown in

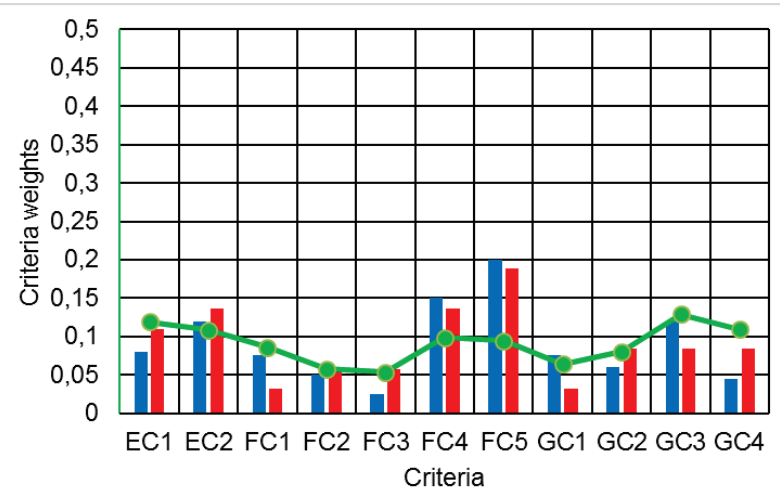

DM1 Direct $\quad$ DM1 RSP $\rightarrow-$ Mean

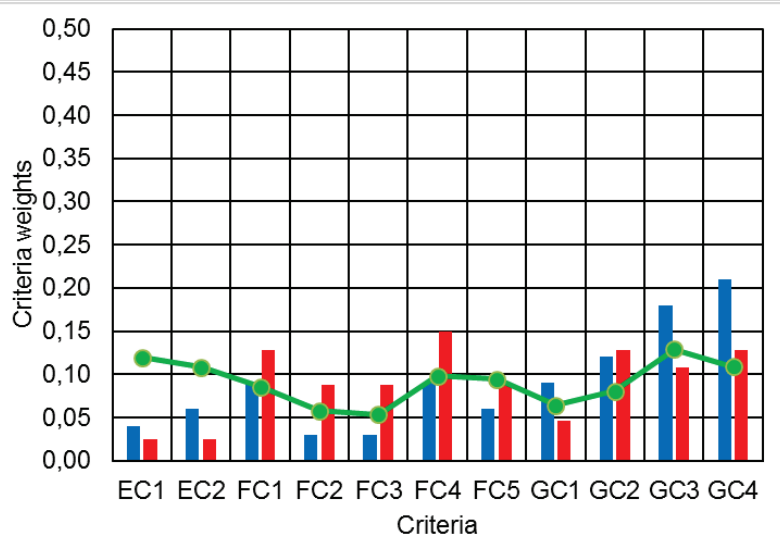

DM3 Direct DM3 RSP $\rightarrow-$ Mean
Fig. 5, while the alternative ranking is shown in Fig. 6.

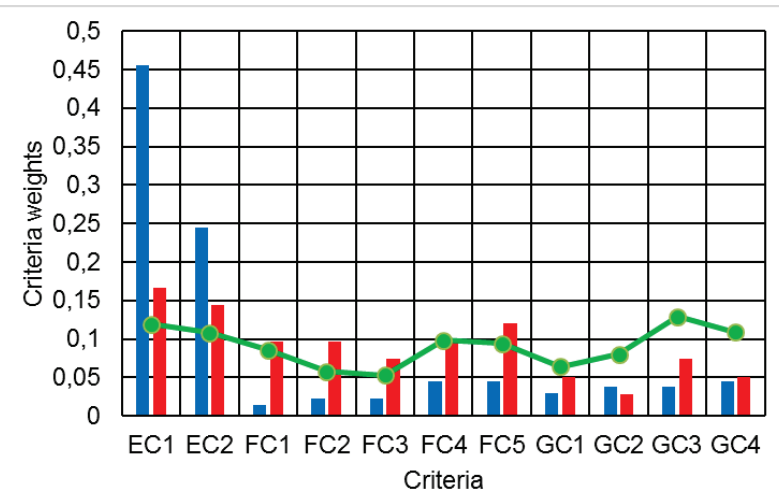

DM2 Direct DM2 RSP $\rightarrow-$ Mean

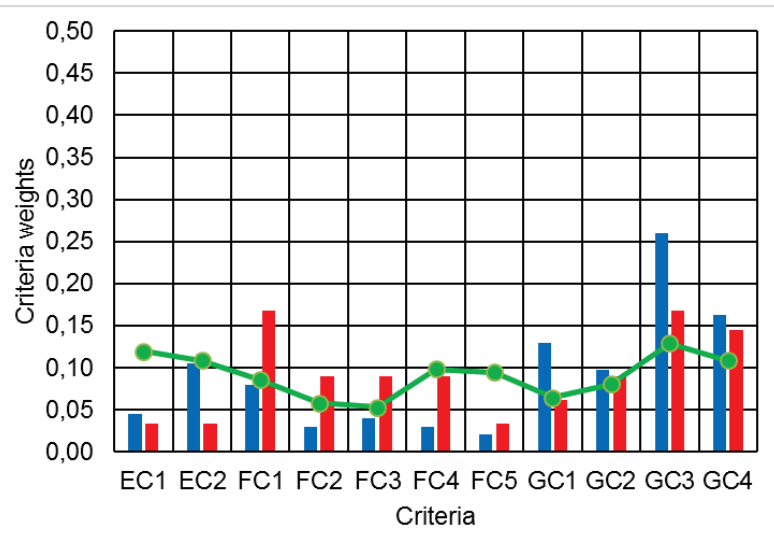

DM4 Direct DM4 RSP $\rightarrow-$ Mean

Figure 4 Criteria weights by DM1-4

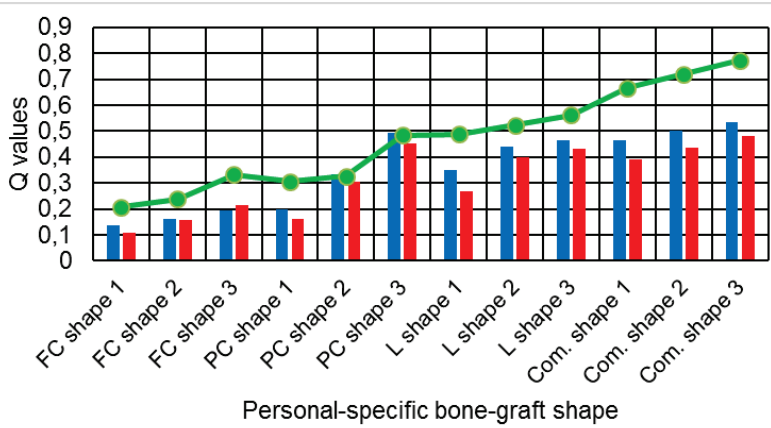

Q - DM1 Direct $\quad Q$ - DM1 RSP $\quad \rightarrow$ Q - Mean

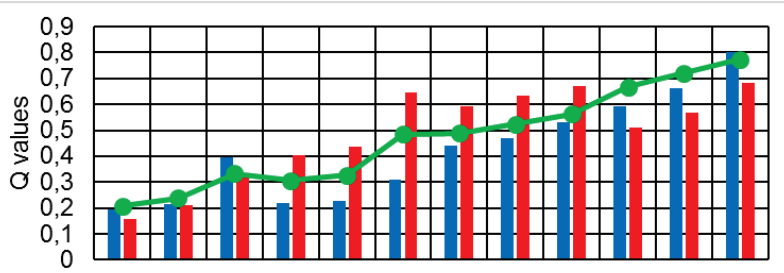

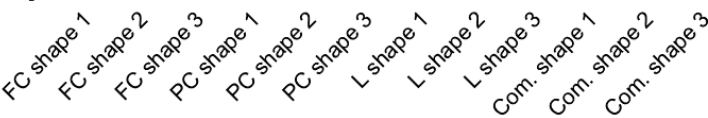

Personal-specific bone-graft shape

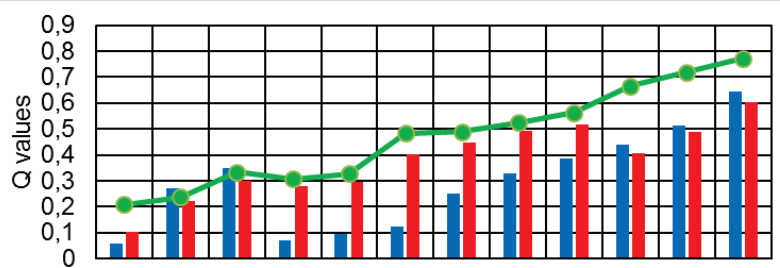

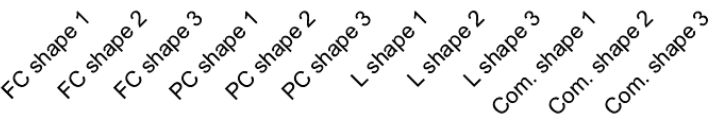

Personal-specific bone-graft shape

Q - DM2 Direct $\quad Q$ - DM2 RSP $\rightarrow Q-$ - Mean

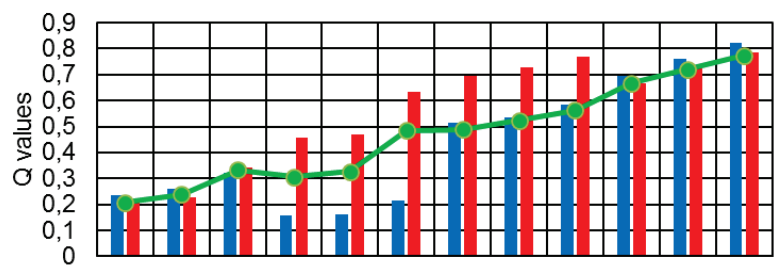

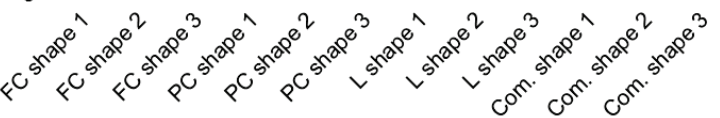

Personal-specific bone-graft shape

Q - DM4 Direct $\quad Q$ - DM4 RSP $\rightarrow Q-$ - Mean

$Q$ - DM3 Direct $\square$ - DM3 RSP $-Q-$ - Mean

Figure $5 \mathrm{Q}$ values from VIKOR 

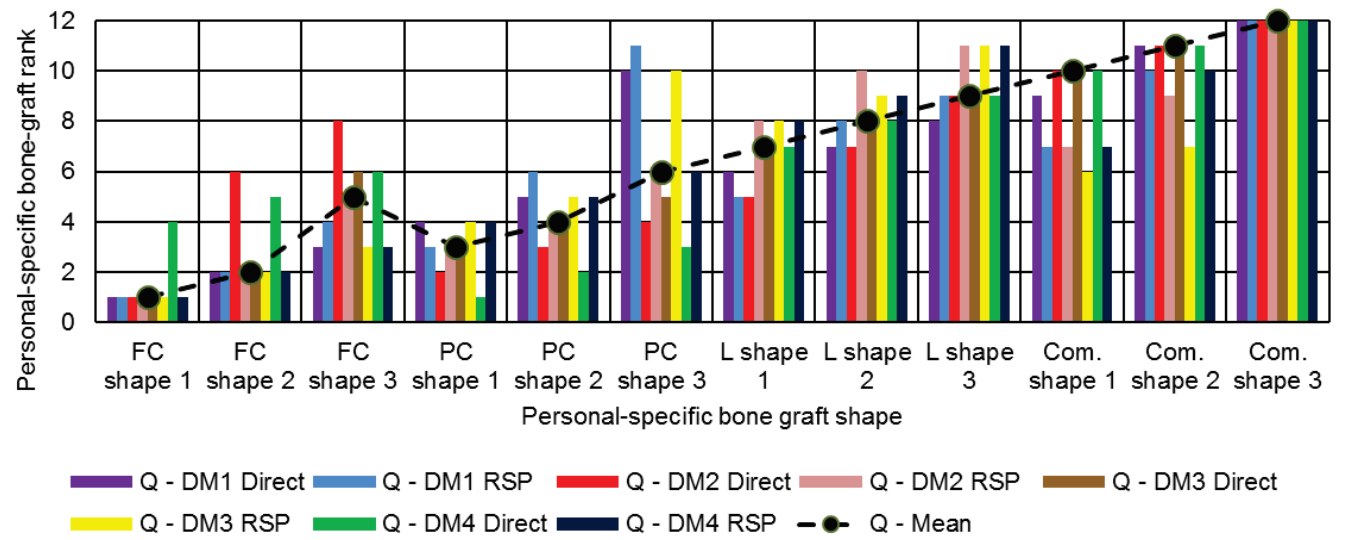

Figure 6 Ranking of patient-specific bone-graft design alternatives

\section{DISSCUSSION}

Based on the presented three case studies, it can be seen that, although presented shapes can be similar, they cannot be applied in the same position on the insertion site. The reason for this is mainly due to their customizability, since each shape should be placed on its predesigned place.

According to calculated criteria weights shown in Fig. 4 , the four decision makers had a different opinion on criteria importance. Although the decision makers were familiar with the weighting procedure by direct weighting and RSP, the use of two weighting methods for expression of decision makers preferences resulted in significantly different criteria weights. Deviations of criteria weighting by two weighting methods are largest for the second and the forth decision maker. Mean values of criteria weights have been calculated as average values of eight sets of criteria weights, where four decision makers expressed their preferences with two weighting approaches. Mean values of criteria weights from four decision makers show that patient-specific bone-graft shape $(G C 3)$ and modelling cost $(E C 1)$ were considered as the most important criteria by the decision makers. This means that values from the performance matrix of $G C 3$ and $E C 1$ will have the largest effect on the ranking of patient-specific bone-graft design alternatives. On the other side, negative angles $(F C 2)$ and sharp edges $(F C 3)$ were considered as the least important criteria in mean value from decision makers weighting.

Results from VIKOR, $Q$ values of alternatives shown in Fig. 5, show that different perspectives in criteria weighting produce a different evaluation of alternatives. Interesting results of $Q$ values are found for $\mathrm{PC}$ shape 1 and 2. $Q$ values for PC shape 1 and 2 have small deviations when compared to PC shape 3 . Here the choice of optimal patient-specific bone-graft can exclude PC shape 3 because of its high complexity and decision makers can select one of the PC shapes 1 or 2 as the best ones. Other reason for exclusion of PC shape 3 could also be the patient-specific bone-graft's thickness-to-size ratio as well since, according to the manufacturer's recommendations, the thickness should not exceed past $3 \mathrm{~mm}$.

In general, if mean values from all eight criteria weighting perspectives (DM1-4, direct weighting and RSP) are used in VIKOR, the MCDA show that FC shape 1 and FC shape 2 are the least complexed designs, and vice versa, complex shapes 2 and 3 are the most complex patientspecific bone-graft designs. This can be concluded also if rankings of patient-specific bone-graft design from Fig. 6 are observed. Fully curved shape 1 is ranked as least complexed patient-specific bone-graft design by 7 out of 8 weighting perspectives. Conversely, complex shape 3 is ranked as the most complex shape by all weighting perspectives. This can be also confirmed based on their geometrical shape, ranging from more simple shapes (FC shape 1 and 2) to the complex shape 2 and 3.

\section{CONCLUSION}

Based on the previously defined framework of criteria in this research, it can be concluded that the complexity of the shape influences the implantation of the selected patient-specific bone-graft shape (Fig. 3). This confirmation from the conducted MCDA approach and the shape design point of view enables high reliability for the selection of optimal design for patient-specific bone-grafts using the proposed MCDA approach. The developed approach aims to help the decision makers and designers during the first stage of patient-specific bone-graft's life cycle, the design phase, and to assure that the optimal design has been delivered for other life cycle stages.

Use of two weighting methods showed that the different weighting procedures yield different criteria weights even if the decision maker has the same preferences for evaluated criteria. Therefore, it is recommended to use more than one weighting method in order to obtain consistent results from the decision makers involved in the weighting procedure.

Although the proposed framework of evaluation criteria covers the most important aspects of patientspecific bone-graft design, the developed MCDA approach is flexible in terms of adding or removing criteria for evaluation of patient-specific bone-graft design complexity. Future research can be focused towards creating a user-friendly software system which will aid interaction of decision makers and designer with MCDA approach in order to select the optimal design for patientspecific bone-grafts. Furthermore, the direction of future research can include analysis of patient-specific bonegrafts that are built from different materials.

\section{Acknowledgement}

Presented results are output from the research made within the project "Research and development of 
modelling methods and processes of manufacturing of dental restorations using modern technology and computer aided system" No. TR35020 funded by the Ministry of Education, Science and Technological Development of Serbia.

\section{REFERENCES}

[1] Parthasarathy, J. (2014). 3D modeling, custom implants and its future perspectives in craniofacial surgery. Annals of Maxillofacial Surgery, 4(1), 9-18. https://doi.org/10.4103/2231-0746.133065

[2] Mirkovic, S., Budak, I., Puskar, T., Tadic, A., Sokac, M., Santosi, Z., \& Djurdjevic-Mirkovic, T. (2015). Application of modern computer-aided technologies in the production of individual bone graft: A case report. Vojnosanitetski Pregled, 72(12), 1126-1131. https://doi.org/10.2298/vsp140915117m

[3] Budak, I., Trifkovic, B., Puskar, T., Vukelic, D., VucajCirilovic, V., \& Hodolic, J. (2013). Comparative Analysis of 3D Digitization Systems in the Field of Dental Prosthetics. Tehnicki Vjesnik - Technical Gazette, 20(2), 291-296.

[4] Peel, S. \& Eggbeer, D. (2016). Additively manufactured maxillofacial implants and guides - achieving routine use. Rapid Prototyping Journal, 22(1), 189-199. https://doi.org/10.1108/rpj-01-2014-0004

[5] Sokac, M., Budak, I., Mirkovic, S., Santosi, Z., Movrin, D., \& Puskar, T. (2017). The role of advanced 3D technologies and additive manufacturing in designing and manufacturing of customized bone grafts. Journal for Technology of Plasticity, 42(2), 33-45. https://doi.org/10.24867/jtp.2017.42-2.33-45

[6] Dahake, S. W., Kuthe, A. M., Mawale, M. B., \& Bagde, A. D. (2016). Applications of medical rapid prototyping assisted customized surgical guides in complex surgeries. Rapid Prototyping Journal, 22(6), 934-946. https://doi.org/10.1108/rpj-02-2015-0021

[7] Singare, S., Lian, Q., Wang, W. P., Wang, J., Liu, Y., Li, D., \& Lu, B. (2009). Rapid prototyping assisted surgery planning and custom implant design. Rapid Prototyping Journal, 15(1), 19-23. https://doi.org/10.1108/13552540910925027

[8] Ebrahimi, M. (2017). Bone Grafting Substitutes in Dentistry: General Criteria for Proper Selection and Successful Application. IOSR Journal of Dental and Medical Sciences, 16(4), 75-79. https://doi.org/10.9790/0853-1604037579

[9] Budak, I., Mirkovic, S., Sokac, M., Santosi Z, Puskar, T., \& Vukelic, D. (2016). An Approach to Modelling of Personalized Bone Grafts Based on Advanced Technologies. International Journal of Simulation Modelling, 15(4), 637648. https://doi.org/10.2507/ijsimm15(4)5.357

[10] Nizam Ahmad, M., Shuib, S., Hassan, A. Y., Shokri, A. A., Ridzwan, M. I. Z., \& Ibrahim, M. N. M. (2007). Application of multi criteria optimization method in implant design to reduce stress shielding. Journal of Applied Sciences, 7(3), 349-355. https://doi.org/10.3923/jas.2007.349.355

[11] Vukelic, D., Budak, I., Tadic, B., Simunovic, G., Kljajic, V., \& Agarski, B. (2017). Multi-criteria decision-making and life cycle assessment model for optimal product selection: case study of knee support. International Journal of Environmental Science and Technology, 14(2), 353-364. https://doi.org/10.1007/s13762-016-1151-8

[12] Jahan, A. \& Bahraminasab, M. (2015). Multicriteria Decision Analysis in Improving Quality of Design in Femoral Component of Knee Prostheses: Influence of Interface Geometry and Material. Advances in Materials Science and Engineering, 1-16. https://doi.org/10.1155/2015/693469
[13] Cavallini, C., Giorgetti, A., Citti, P., \& Nicolaie, F. (2013). Integral aided method for material selection based on quality function deployment and comprehensive VIKOR algorithm. Materials \& Design, 47, 27-34.

https://doi.org/10.1016/j.matdes.2012.12.009

[14] Deal, C., Tony, M., Khoury, H., Nesrallah, G., Al-Jaishi, A. A., \& Goetghebeur, M. (2017). MCDA for the Development of Clinical Practice Guidelines and for the Prioritization Clinical Research Questions. Multi-Criteria Decision Analysis to Support Healthcare Decisions, 239-273. https://doi.org/10.1007/978-3-319-47540-0_13

[15] Garau, M., Hampson, G., Devlin, N., Mazzanti, N. A., \& Profico, A. (2018). Applying a Multicriteria Decision Analysis (MCDA) Approach to Elicit Stakeholders' Preferences in Italy: The Case of Obinutuzumab for Rituximab-Refractory Indolent Non-Hodgkin Lymphoma (iNHL). PharmacoEconomics, 2(2), 153-163. https://doi.org/10.1007/s41669-017-0048-x

[16] Frazao, T.D.C., Camilo, D.G.G., Cabral, E.L.S., \& Souza, R.P. (2018). Multicriteria decision analysis (MCDA) in health care: a systematic review of the main characteristics and methodological steps. BMC Medical Informatics and Decision Making, 18(1). https://doi.org/10.1186/s12911-018-0663-1

[17] Baran-Kooiker, A., Czech, M., \& Kooiker, C. (2018). MultiCriteria Decision Analysis (MCDA) Models in Health Technology Assessment of Orphan Drugs - A Systematic Literature Review. Next Steps in Methodology Development? Frontiers in Public Health, 6. https://doi.org/10.3389/fpubh.2018.00287

[18] Crnjac, M., Aljinovic, A., Gjeldum, N., \& Mladineo, M. (2019). Two-stage product design selection by using PROMETHEE and Taguchi method: A case study. Advances in Production Engineering \& Management, 14(1), 39-50. https://doi.org/10.14743/apem2019.1.310

[19] Szafranko, E. (2017). Applicability of multi-criteria analysis methods for the choice of material and technology solutions in building structures. Tehnicki Vjesnik - Technical Gazette, 24(6), 1935-1940. https://doi.org/10.17559/tv-20150810135440

[20] Vilke, S., Krpan, L., \& Milkovic, M. (2018). Application of the Multi-Criteria Analysis in the Process of Road Route Evaluation, Tehnicki Vjesnik - Technical Gazette, 25(6), 1851-1859. https://doi.org/10.17559/TV-20170530085451

[21] Šarić, T., Šimunović, K., Pezer, D., \& Šimunović, G. (2014). Inventory classification using multi-criteria ABCanalysis, neural networks and cluster analysis. Tehnicki Vjesnik Technical Gazette, 21(5), 1109-1115

[22] Jiang, H. \& Liu, C.Y. (2019). Scheduling Optimization of Cloud Resource Supply Chain through Multi-Objective Particle Swarm Optimization. International Journal of Simulation Modelling, 18(1), 163-174. https://doi.org/10.2507/ijsimm18(1)co3

[23] Boas, F. E. \& Fleischmann, D. (2012). CT artifacts: causes and reduction techniques. Imaging in Medicine, 4(2), 229240. https://doi.org/10.2217/iim.12.13

[24] Figueira, J. \& Roy, B. (2002). Determining the weights of criteria in the ELECTRE type methods with a revised Simos' procedure. European Journal of Operational Research, $139(2), 317-326$. https://doi.org/10.1016/S0377-2217(01)00370-8

[25] Andre, P. \& Simos, J. (1990). Évaluer l'impact sur l'environnement. Une approche originale par l'analyse multicritère et la négotiation. Coll. Meta, Presses polytechniques et universitaires romandes. Géographie Physique et Quaternaire, 47(1), 126. https://doi.org/10.7202/032939ar

[26] Maystre, L. Y., Pictet, J., \& Simos, J.(1994). A review of: Méthodes multicritres ELECTRE: description, conseils pratiques et cas d'application la gestion environnementale. 
European Journal of Engineering Education, 19(4), 517-517. https://10.1080/03043799408928313

[27] Opricovic, S. \& Tzeng, G. H. (2004). Compromise solution by MCDM methods: A comparative analysis of VIKOR and TOPSIS. European Journal of Operational Research, 156(2), 445-455. https://doi.org/10.1016/s0377-2217(03)00020-1

\section{Contact information:}

\section{Boris AGARSKI, Dr. Sc.}

(Corresponding author)

University of Novi Sad, Faculty of Technical Sciences,

Trg Dositeja Obradovica 6, Novi Sad, Serbia

E-mail: agarski@uns.ac.rs

\section{Mario SOKAC, MSc}

University of Novi Sad, Faculty of Technical Sciences,

Trg Dositeja Obradovica 6, Novi Sad, Serbia

\section{Zeljko SANTOSI, MSc}

University of Novi Sad, Faculty of Technical Sciences,

Trg Dositeja Obradovica 6, Novi Sad, Serbia

\section{Djordje VUKELIC, Dr. Sc}

University of Novi Sad, Faculty of Technical Sciences,

Trg Dositeja Obradovica 6, Novi Sad, Serbia

Igor BUDAK, Dr. Sc.

University of Novi Sad, Faculty of Technical Sciences,

Trg Dositeja Obradovica 6, Novi Sad, Serbia 